Archivum, LXXI, 2021, pp. 7-42

\title{
La actualidad del teatro de Lope de Vega en la década de 1930: presencia en la cartelera española y recepción
}

\author{
María Álvarez Álvarez \\ UNIVERSIDAD DE OviEdo \\ alalvarezmaria@gmail.com
}

Recibido: 08/02/2021

Aceptado: 18/06/2021

\section{RESUMEN:}

El objetivo del presente artículo es repasar la presencia del teatro de Lope de Vega en la cartelera española de la década de 1930, con especial atención a la madrileña, atendiendo a la recepción de sus puestas en escena y a la interpretación que se dio a sus piezas. En estos años, paulatinamente, el teatro clásico comenzó a ofrecer muestras del avance escenográfico y la renovación dramatúrgica que los críticos venían reclamando para la escena española desde la década anterior: en este sentido, el teatro de Lope de Vega adquiere especial relevancia, pues, además de tratarse de uno de los autores áureos más populares de la época, su obra conoció especial atención por la celebración del tercer centenario de su muerte en 1935. Además, las turbulentas circunstancias sociopolíticas de estos años conectaron una de sus piezas, Fuente Ovejuna, con la actualidad española del momento.

PALABRAS CLAVE: Lope de Vega. Siglo de Oro. Teatro clásico. Teatro español del siglo XX. Renovación escénica. 
The relevance of Lope de Vega's theatre in the 1930s:

Its presence on the Spanish stage and its reception

\begin{abstract}
:
This article analyses the presence of Lope de Vega's theatre on the Spanish stage of the 1930s, with special attention to the plays staged in Madrid, and focusing on its reception and interpretation. In these years, classical theatre began to offer samples of the dramaturgical renovation that critics had been demanding for the scene since the previous decade. In this sense, the case of Lope de Vega is especially interesting, since he is one of the most popular Golden Age authors of the time, and because of the celebration of the tercentenary of his death, in 1935. Furthermore, the turbulent socio-political circumstances of these years connected one of his plays, Fuente Ovejuna, with the Spanish reality at the time.
\end{abstract}

KEYWORDS: Lope de Vega. Golden Age. Spanish classical theatre. 20th Century Spanish Theatre. Scenic renovation.

Durante los años 20 del pasado siglo, las páginas de la prensa fueron testigo de un intenso debate en torno al ambiente de crisis y mediocridad que dominaba el panorama teatral del momento y a la búsqueda de una renovación escénica que ya se estaba dando con éxito fuera de nuestras fronteras. La dramaturgia española necesitaba desprenderse de las caducas imposiciones decimonónicas y abrirse a propuestas más innovadoras y vanguardistas, en lo que el teatro clásico y la libertad de los autores barrocos podían jugar un importante papel, como reclaman críticos y dramaturgos y como se venía demostrando en Francia, Alemania o Rusia ${ }^{1}$. Mientras tanto, en España, las piezas clásicas apenas eran representadas y se ofrecían a través de refundiciones que modificaban profundamente los originales para adaptarlos a las prácticas del momento o al lucimiento de un divo (Oliva, 2011, 161-163). De Lope de Vega, por ejemplo, objeto de nuestro estudio y uno de los autores áureos más populares en la época, solo encontramos cinco obras en la cartelera

1 Sobre todo ello, pueden consultarse los clásicos estudios de Dougherty (1983 y 1984). 
madrileña entre 1918 y 1929 (Dougherty y Vilches, 1990 y 1997): La niña boba, La Estrella de Sevilla (de autoría aún hoy incierta, pero que en la época se atribuía a Lope), El castigo sin venganza y, en una ocasión, Las famosas asturianas (en refundición de Muñoz Seca, de 1918) y La niña de plata (1926)²; a ello se suma las pocas funciones ofrecidas de cada pieza, que rara vez alcanzaban la decena en un momento en el que el éxito significaba llegar o acercarse a las cien.

Pero de cara a la década de 1930 se observa un paulatino cambio en lo que se refiere a la representación de los clásicos: las reivindicaciones de la prensa que mencionábamos comienzan entonces a obtener frutos en el plano real, no solo teórico, y esto incumbe particularmente al teatro de Lope de Vega por dos razones en especial: la celebración del tercer centenario de su muerte en 1935 - que por fortuna tuvo sus consecuencias en el plano teatral- y la relevancia que en este periodo adquirió una de sus obras, Fuente Ovejuna, por motivos extraliterarios: la presencia y la recepción del teatro de Lope nos interesará ahora desde un punto de vista artístico, estético, pero también histórico, social, incluso político. El cambio dado en este periodo se reflejará tanto en el número de obras representadas, como en la actitud de los responsables de las adaptaciones, cada vez más respetuosos, y en sus puestas en escena, que ganan en calidad y se acercan a las nuevas propuestas escenográficas que se reclamaban para el teatro en España.

\section{Los inicios de un cambio}

Un vistazo a la tabla 1 incluida en el apéndice basta para observar varios datos relevantes: el considerable aumento de piezas de Lope representadas alrededor de 1935, ya mencionado, así

2 Además, se ha localizado un montaje de Peribáñez a cargo de El Cántaro Roto, ofrecido en el Círculo de Bellas Artes de Madrid el 11 de noviembre de 1926, que en buena medida vendría a recuperar del olvido la pieza, aunque Pedraza Jiménez $(2002,32)$ se inclina a pensar que no se trataría de una representación íntegra, sino de una "muestra antológica". 
como del número de representaciones ofrecidas, y la frecuencia de reposiciones de los montajes hasta entonces, especialmente en los inicios de la década. En estos años, vuelven a subir a los escenarios las refundiciones que las compañías de María Guerrero López y Fernando Díaz de Mendoza y Guerrero ${ }^{3}$ y de Ricardo Calvo Agostí venían ofreciendo desde hacía años, en ocasiones heredadas de sus predecesores ${ }^{4}$. Precisamente, que se trate de reposiciones ya conocidas de las obras explicaría el escaso interés que despertaron y el poco espacio que les dedica la prensa, cuyas reseñas dan a entender que estas funciones se trataron más de un acto de sociedad que de un evento artístico. En cuanto a La niña boba o Buen maestro es el amor (1931), se trata de la versión de Luis Suñer Casademunt, publicada en 1913, con la que la compañía habría inaugurado el Teatro Cervantes de Buenos Aires en septiembre de 1921 y que habría sustituido la anterior refundición representada por la compañía desde el siglo anterior, una versión heredera de la de Dionisio Solís (responsable del cambio de título de la comedia original, que pasa de ser dama a niña) ${ }^{5}$. Ricardo Calvo, por su parte, vuelve a subir al escenario la refundición de Carlos Moor de El castigo sin venganza en diciembre de 19316, dentro de una "semana popular" que incluía otros títulos habituales en su repertorio: Reinar después de morir, de Vélez de Gue-

3 Se trata del matrimonio formado por la sobrina de María Guerrero, la Brava, y el hijo de esta y Fernando Díaz de Mendoza, continuadores y herederos de la fama y prestigio que la pareja original había alcanzado a finales del siglo XIX.

4 En provincias, como puede observarse en la tabla 2, las obras localizadas se limitan a las pocas funciones que estas compañías llevaban de gira.

5 Sobre las distintas versiones de la pieza, véanse los artículos de Pedraza Jiménez (2002) y Cienfuegos Antelo (2016).

6 Mancebo Salvador (2018) repasa la poca fortuna que ha tenido hasta hace poco la pieza en los escenarios españoles y extranjeros. En la tabla de representaciones que incluye no aparece esta representación (con casi total seguridad por tratarse de una reposición: sí recoge la estrenada en 1919 por la compañía de Ricardo Calvo y Jacinto Benavente; seguramente se trate de la misma versión), ni la de la Cooperativa de Artistas Reunidos, estrenada en 1935 y llevada de gira por provincias a lo largo de ese año, con motivo del tricentenario lopesco. En septiembre de ese mismo año, parece que el Teatro Dramático de Helsingborg (Suecia) la llevó a escena por el mismo motivo (Álvarez Álvarez, 2019, 179). 
vara, Los intereses creados, de Benavente, En Flandes se ha puesto el sol, de Marquina, La petenera, de los hermanos Álvarez Quintero, y De mala raza, de Echegaray. Desde algún diario se advierte que la obra no era, "como se sabe, de lo mejor del fecundísimo Lope", con sus "grandes defectos" (Paredes, 1931), sorprendente afirmación que podría achacarse a la refundición hecha y que, en tal caso, nos diría mucho sobre ella. Por lo demás, la prensa aplaude la decisión de subir al escenario una pieza clásica, suceso casi excepcional en el momento, por el significativo valor artístico que ello suponía. En este sentido, se alaba la labor divulgadora y educadora que Calvo venía llevando a cabo con su apuesta por los clásicos, aunque algún crítico advierte varios fallos en la puesta en escena y vicios en los actores secundarios, cuestiones que "es preciso atender con severidad, para bien de los actores y del público, este público de un nivel cultural quizá escaso, pero respetuoso y de buena fe" (Paredes, 1931).

Un cambio lo suponen ya otras dos obras que encontramos a principios de la década: La moza de cántaro (1930) y El perro del hortelano (1931). El responsable de la primera es una de las piezas claves para el teatro español del siglo $X X$ y, en especial, en estas primeras décadas, el considerado primer director de teatro en sentido moderno de España, Cipriano de Rivas Cherif ${ }^{7}$, buen conocedor de las técnicas escenográficas de la vanguardia europea y en cuya visión reformadora el teatro clásico ocupaba un importante lugar, como él mismo reconoce:

Llevé a cabo en ese tiempo, ante el público en general, compitiendo con la vulgaridad de los demás empresarios, la misma obra emprendida con mis pequeños públicos colaboradores en tantos ensayos y tanteos azarosos. Realicé, con medios más adecuados, el mismo programa de revalorización integral de los autores que tenemos por clásicos españoles y de alumbramiento de los valores nuevos. Lope, Tirso, Calderón, reivindicados en la pureza de

$7 \mathrm{Al}$ respecto debe consultarse el fundamental trabajo de Aguilera Sastre y Aznar Soler (2000). 
sus textos, hollada y maltrecha por refundiciones desgraciadas casi siempre (Rivas Cherif, 1991, 42-43).

Él mismo se encargaría tanto de la adaptación como de la dirección de la comedia, que resultó un verdadero éxito de crítica y de público; este respondió positivamente, a pesar de lo cual la pieza no alcanzó un elevado número de funciones, quizá debido a que los espectadores estaban acostumbrados a otro tipo de puestas en escena de teatro clásico y este no despertaba su interés. Las reseñas destacan, en general, la refundición en diez cuadros llevada a cabo por Rivas Cherif: Araujo-Costa (1930) reconoce el "tacto exquisito" demostrado por el director a la hora de "restaurar" la versión original de Lope tras la versión de Tomás Luceño de principios de siglo, devolviendo así la obra a "las líneas, la forma y el lenguaje en que la [sic] dio alma" su autor. La breve reseña de Arturo Mori (1930) en El Liberal sirve para ejemplificar sobradamente la actitud de la crítica ante esta pieza y la práctica de las refundiciones en general:

A Lope no se le debe utilizar como ensayo de refundiciones. Es demasiado jugoso, demasiado interesante y vario. Hay que llevar al teatro sus obras con todo lo que tienen dentro, como ha hecho Rivas Cherif con La moza de cántaro, arreglo cuidado y respetuoso, para el que ha hecho uso del fanal, y no de las tijeras profanas y cobardes.

Los decorados de Colmenero, bien entendidos en el sentido moderno, facilitaban la rapidez de las mutaciones, y la dicción de Isabel Barrón, primera actriz, destacaba frente a la habitual torpeza de los intérpretes a la hora de recitar en verso. El crítico de La Esfera comenta el poco éxito de público que solía tener el teatro clásico por entonces, debido en buena parte a las malas interpretaciones, e insiste en la necesidad que los espectadores tenían de ser educados en la materia; para ello, deposita sus esperanzas en el director madrileño: "todo se andará si Rivas Cherif persiste en sus proyectos plausibles" (Miquis, 1930). 
Por su parte, los hermanos Manuel y Antonio Machado ${ }^{8}$ se ocuparon de la adaptación de una comedia totalmente desconocida por el público de entonces, El perro del hortelano ${ }^{9}$. La labor de los poetas adaptando varias comedias clásicas era una muestra más de su sólido conocimiento del periodo áureo y su respeto y admiración hacia la literatura del periodo; en concreto, desde mediados de los años 20, refundieron una pieza de Calderón, El príncipe constante, y otras tres de Lope: ;Ay, verdades, que en amor...!, La viuda valenciana y La niña de plata ${ }^{10}$. Todas ellas entraban en el plan de renovación de las tablas en España, del que querían participar y en el cual la comedia áurea se prestaba como un excelente campo para la investigación y la experimentación.

La tan comentada cuestión de la refundición de las obras clásicas vuelve a surgir en este momento ante la actuación de los Machado: pese a la "grima" que le provocaba a algún crítico insistir una vez más en el tema (Masip, 1931), se hace obligatorio debido a la importancia que adquiere. En esta ocasión, en general, se aplaude la labor de los hermanos, que deciden no añadir versos propios a los del original, como el propio Manuel declara: "para Lope son todas nuestras admiraciones y todos nuestros respetos y nos consideramos indignos de promiscuar nuestra modesta inspiración con la suya genial" (González Olmedilla,

8 En algunos lugares consta como tercer responsable de la refundición José López Pérez-Hernández, aunque la prensa informa de que se trata de un "trámite burocrático" (Masip, 1931) cuya razón de ser desconocemos.

9 Tanto esta obra como la ya mencionada La niña boba son ofrecidas pocos días antes en el Teatro Circo de Albacete, como puede verse en la tabla 2. Para la reconstrucción (parcial) de las carteleras en provincias previas a 1935, se han consultado las tesis de Ochando Madrigal (1998), González Blanch (2004), Somalo Fernández (2004) y Vázquez Honrubia (2004), que estudian las carteleras de Albacete, Segovia, Logroño y Llanes a principios del siglo XX. Se ha completado con la información recogida en Romera Castillo (2012). También debemos mencionar la obra de Marrast (1978) para lo que se refiere al teatro durante la Guerra Civil.

10 A ellas habría que añadir la refundición de La malcasada, también de Lope, que Manuel Machado dejó inacabada a su muerte en 1947, terminada por José M. a Pemán y Agustín González. Romero Ferrer (1998) estudia la labor de los hermanos con el teatro clásico. 
1931). Si bien admiten haber cortado "algunas escenas completamente secundarias [...] que distraían al espectador de la trama principal", los amores entre la condesa de Belflor y su secretario, sabemos gracias a las reseñas que también eliminaron los cambios de lugar (ahora toda la comedia transcurre en una sala del palacio de Diana) y redujeron el tiempo del original. Aunque algún crítico rechaza los cambios realizados por considerar que así la comedia quedaba "contrahecha" (Masip, 1931), en general estos son acogidos positivamente y felicitan a los poetas por su decisión de no intervenir en la pieza de Lope con versos de su propia cosecha, como Enrique Díez-Canedo (1931): “Ojalá todas las adaptaciones se hicieran con este tacto".

La pieza original es alabada por la riqueza de sus imágenes, la belleza y frescura de sus versos (que recuerdan a otros autores, como Moreto o Tirso) y, sobre todo, por su modernidad y por la creación de complejos y "efectivos caracteres dramáticos" (Alsina, 1931), especialmente el personaje de la protagonista: la agudeza y sensibilidad de Lope se manifiestan en ella, creando un personaje eterno, "no de su siglo, sino mujer de todos los tiempos, completamente libertada de las trabas de la época", cuestión en la que coinciden varios críticos. También se destaca la "íntima voluptuosidad" (Díez-Canedo, 1931) y la pasión que rezuma la comedia, que logra vencer las imposiciones sociales, aunque es llamativa la lectura realizada por algún crítico, que ve en Diana un

ejemplo de honestidad y recato, mientras lucha con un amor sincero, honrado, confesable, pero que se opone a sus deberes para con su casa y su familia. Así proceden las damas españolas, ahí está el camino de la corrección en la conducta si no queremos que el orden natural de las sociedades se confunda y nos lleve a la oscuridad y al desconcierto (Araujo-Costa, 1931).

Anselmo González Fernández, tras su seudónimo de Alejandro Miquis (1931), pone en relación la obra con un estreno con- 
temporáneo, el de El hombre deshabitado, auto de Rafael Alberti estrenado la noche del 26 de febrero en el Teatro de la Zarzuela. Las dos piezas, una clásica (pero de espíritu moderno) y otra vanguardista, "completamente dispares en apariencia al menos", representan los dos puntos extremos de una evolución del teatro español, que iba desde la grandeza alcanzada en los Siglos de Oro hasta la actualidad, en la que el teatro debía expresar la complejidad del hombre moderno, pero sin rechazar ni un extremo ni otro, sino valorándolos y cultivando ambos. La buena acogida del público la noche del estreno se vio reflejada en el número de representaciones (veintisiete), que destaca dentro del panorama de la época.

Otra pieza que alcanzó un número meritorio (si bien aún bajo en términos generales) por las mismas fechas fue Fuente Ovejuna, estrenada ya en periodo republicano, en enero de 1932: la fecha es importante, pues su refundidor, el poeta y dramaturgo Enrique López Alarcón, quiso vincular la obra al momento sociopolítico mediante ciertas modificaciones y eliminaciones respecto al original. De hecho, el número de representaciones alcanzadas pudo deberse más al mensaje y al contexto sociopolítico en el que se dio que a la calidad artística alcanzada.

Fuente Ovejuna, como se sabe, había sido recuperada del olvido a finales del siglo XIX, cuando Menéndez Pelayo (1949, 175176) la tildó de "democrática" y destacó su "arranque revolucionario", y, a través de los montajes soviéticos de la pieza (que no dudaron en utilizarla como propaganda política eliminando toda alusión a los monarcas) $)^{11}$, esta fue acumulando popularidad, más por el supuesto mensaje político que podía trasladar a la sociedad de principios del siglo XX que por sus cualidades

11 El montaje de Mardzhanov de 1919 estableció por primera vez la pauta de alterar el desenlace original, eliminando las figuras de los Reyes Católicos, lo que sería imitado en posteriores montajes de la pieza (Weiner, 1982, 183). A partir de entonces, y hasta 1938, la pieza se encuentra al menos una vez al año en los escenarios soviéticos, convertida ya en arma de propaganda del régimen. Durante los años que nos ocupan, la carga emocional de la obra no podrá desprenderse de la fama que estas representaciones de signo político le otorgan (Kirschner, 1977, 259). 
literarias. En España, la consolidación de la popularidad de la pieza la traerán las funciones de La Barraca, que la estrenará en el verano de 1933 en Valencia: la decisión de Lorca de ofrecer una "antología" de Fuente Ovejuna, que prescindía del denominado drama político y se centraba en el social (los abusos del comendador en la villa cordobesa), fue a menudo malinterpretada y puesta en relación con las adaptaciones soviéticas, buscando en ella una lectura política que los barracos no deseaban. Antes de esta versión, en España, la obra había subido a las tablas del Español en octubre de 1903, refundida por Valle-Inclán y Manuel Bueno (Gago Rodó, 1997), y ahora, en 1932, la compañía de Enrique Borrás sube al mismo escenario la refundición de López Alarcón, esta sí cargada de una clara intencionalidad política. Como estudia Dougherty (2013), esta lectura de la pieza coincide en el tiempo con una búsqueda, por parte de la recién nacida República y sus intelectuales, de una identidad democrática, liberal, incluso revolucionaria, del pueblo español ${ }^{12}$, que ponía en el centro de la vida política y social la soberanía popular: con ella, López Alarcón pretende celebrar la llegada del nuevo régimen y la reciente aprobación (en diciembre de 1931) de su constitución.

Con ello en mente, el refundidor introduce importantes modificaciones en el texto de Lope (véase al respecto el mencionado artículo de Dougherty, 2013): elimina los personajes de los Reyes Católicos, sus escenas y referencias a ellos, así como las relativas al Maestre de Calatrava, con la consecuente reducción de lugar, centrando la obra en el conflicto entre el comendador y los villanos. Las sustituciones y ampliaciones de texto son muy reveladoras en cuanto a la actualización del mensaje, en una búsqueda de igualar los personajes de los campesinos y los reyes, poniendo

12 En este sentido, Rodríguez-Solás (2014) estudia cómo los planes políticos y culturales de la República utilizaron el teatro clásico como una herramienta para la consolidación de su régimen, buscando en él nuevas formas de interpretación de la identidad española, distintas a las que venían siendo tradicionalmente divulgadas. Ello explicaría su apoyo e impulso a proyectos como el de La Barraca o las Misiones Pedagógicas. 
por encima de todos ellos la ley, en un claro guiño a la recién aprobada constitución. Así, por ejemplo, se ve en los siguientes versos, que sustituyen, significativamente, "reyes" por "leyes" (los ejemplos provienen de Dougherty, 2013, 132-134):
¡Vivan los reyes famosos
muchos años, pues que tienen
la victoria, y a ser vienen
nuestros dueños venturosos!
Salgan siempre victoriosos
de gigantes y de enanos
y ¡mueran los tiranos!
¡Vivan las leyes famosas
muchos años, pues que tienen
la victoria, y a ser vienen
nuestras dueñas venturosas!
Salgan siempre victoriosas
de gigantes y de enanos
y ¡mueran los tiranos!

El pueblo se somete ahora a unas leyes justas para todos, no a la voluntad de los monarcas, que, si bien en el teatro de Lope personificaban la justicia, no era así en el contexto de la España republicana. También el nuevo cierre de la comedia, puesto en boca de Frondoso, une de forma explícita la rebelión ficticia y la actualidad española: “...una pieza en cuya trama / dio Lope de Vega el drama / de la España porvenir".

Ante todos estos cambios, la respuesta de la crítica fue desigual: tanto Felipe Paredes (1932), como Bernardo G. de Candamo (1932), por ejemplo, aplauden la labor refundidora llevada a cabo, como también hace el anónimo crítico de Ahora (31-1-1932), para el cual esta versión hacía posible la difícil tarea de acercar al público la obra de Lope, conservando, además, "las esencias puras" del original: pese a la distinta disposición escénica o la 
supresión de personajes importantes, la obra había ganado en ritmo y en sencillez interpretativa, puesto que, en su opinión, la forma original distraía y quitaba importancia al verdadero protagonista de la obra: el pueblo.

La mayoría, en cambio, se muestra descontenta ante esta versión: Enrique Díez-Canedo (1932) considera que el refundidor había ido demasiado lejos con sus cortes "en aras de actualidad", aunque reconoce que la nueva versión llegaba en un momento en el que la coyuntura política interpelaba la tragedia original con "una emoción viva, un resplandor actual". Tampoco la puesta en escena es de su gusto, considerando en conjunto la representación como "inadmisible" para un teatro como el Español: a la falta de ensayos y los fallos en los decorados (que entorpecían el movimiento en una obra en la que este es tan relevante), se unía el grave error de haber reducido toda la acción a un solo lugar, lo que provocó que algunas escenas y transiciones resultasen "intolerables", pues la variedad de escenarios en esta pieza no es, en su opinión, caprichosa, sino "esencial"; ante la pobreza material de los escenarios españoles de la época, Díez-Canedo aboga entonces por la sencillez escénica, "el recurso de suprimir toda escenografía". Coinciden con él Antonio Espina (1932) y Melchor Fernández Almagro (1932), que tampoco se muestran favorables ni a la refundición ni a la representación: el primero califica de "lamentable" la puesta en escena, critica la desastrosa interpretación y la caracterización de los actores, así como el decorado de Salvador Alarma, "viejo, cursi, desentonado, agrio", y echa a faltar la arenga de Laurencia en el tercer acto, uno de los momentos álgidos de la pieza. Fernández Almagro se centra en dos cuestiones muy discutidas por entonces: la labor del refundidor y la vanguardia escenográfica. Continúa reclamando la presencia de los clásicos en escena, pero, en esta ocasión, echa de menos mayor respeto por parte de López Alarcón:

Pero obra que por refundida se ofrezca desvirtuada difícilmente se animará con provecho y honra; más bien contribuirá a des- 
pistar el gusto general y a influir en falsas nociones. Así esta Fuenteovejuna de ahora. [...] Circunstancias propias de cada caso dan derecho al refundidor para ejecutar su cometido con alguna flexibilidad. Cuestión, al cabo, de buena mano, de medida. Cortar quizá, nunca añadir. Someterse siempre - ¡no faltaba más! - al espíritu general de la obra; no traicionarla haciendo fuerza en alguna de sus significaciones. Acercar una obra clásica al corazón de públicos muy posteriores no es acomodarla rectificando, sino mantenerla en todos los perfiles esenciales cuando menos.

En cuanto a la puesta en escena, él también lamenta la falta de recursos generalizada en los teatros españoles, que impedía un mayor lucimiento de esta y otras piezas: “La escenografía moderna sacaría de nuestras comedias de capa y espada, de esta tragedia o auto, de aquel cuadro de costumbres con luces y colores de ahora, efectos verdaderamente insospechables". Fuera de España, las vanguardias encontraban en el teatro clásico una fragua para su dramaturgia, mientras que aquí sus moldes eran destruidos a base de torpes refundiciones y tristes puestas en escena (Miquis, 1932). González Olmedilla (1932), favorable tanto al decorado como a la "dignísima" interpretación, denuncia él también la "penuria teatral" que se había hecho patente: en otras circunstancias, una representación de Fuente Ovejuna habría supuesto un magnífico acontecimiento teatral, capaz de rivalizar con el temido cinematógrafo, pero en esta ocasión faltaron la "audacia y, sobre todo, [el] dinero".

Otros diarios de corte más conservador también critican negativamente el montaje, aunque en estos casos parecen pesar más razones ideológicas, y se centran, sobre todo, en una defensa de la institución monárquica: Un Espectador Sencillo (1932) aprovecha para desplegar un largo preludio en defensa del tradicionalismo español antes de pasar a tratar la versión, que encuentra tendenciosa y deplorable, y Araujo-Costa (1932) denuncia la "pluma pecadora" de López Alarcón y los "inoportunos" versos finales en boca de Frondoso. 


\section{Un oasis en 1935: el tricentenario}

El panorama cambiará radicalmente de cara al tricentenario, y no solo en cuanto al tratamiento de los textos y puesta en escena, o número de obras representadas y funciones ofrecidas, sino también en lo que respecta a la recepción que estas tendrán en los periódicos: las circunstancias sociopolíticas derivadas de la revolución de octubre del 34 provocaron una radicalización general del ambiente a lo largo del año siguiente, lo que tuvo su reflejo en la prensa, que también radicalizó sus posturas ${ }^{13}$. El estudio del tricentenario lopesco ha ido acaparando cada vez más atención desde inicios del siglo XXI (Álvarez Álvarez, 2019, 23-35): dentro de las múltiples actividades conmemorativas que surgieron durante la efeméride, la representación de piezas lopescas ocupó un lugar primordial, tanto entre profesionales del teatro como por parte de grupos de aficionados, desde los más humildes a los de mayor categoría y prestigio. Dado el alto número de obras llevadas a escena este año, nos centraremos a continuación en los datos que nos han parecido más relevantes para el presente estudio; para un análisis más detenido del tema, remitimos a los trabajos de Iglesias (1999 y 2002), Aguilera Sastre y Aznar Soler (2000), García Santo-Tomás (2000), Gil Fombellida (2003), Zamora Muñoz (2015 y 2019) o Álvarez Álvarez (2019), entre otros.

Como mencionamos anteriormente, 1935 destaca dentro del panorama general por concentrar un elevado número de obras de Lope: como puede observarse en la tabla 1, con ocasión del tricentenario encontramos trece piezas llevadas a los escenarios madrileños por parte de compañías profesionales, ocho de ellas dentro del circuito comercial y cinco que formaron parte de homenajes públicos o privados: La esclava de su galán, que se

13 Florit Durán (2000) destaca cómo durante este año las cuestiones ideológicas prevalecieron muy a menudo sobre las literarias y culturales, aspecto que también señala García Santo-Tomás (2000) en su imprescindible obra acerca de la recepción del teatro lopesco. Sobre el caso concreto de la prensa, en Álvarez Álvarez (2019) se realiza un análisis del peso que tuvo la ideología en el tratamiento de la figura de Lope y su conmemoración a través de las páginas de los diarios. 
representó en el Círculo de Bellas Artes como parte de su fiesta dedicada a Lope, y el entremés El degollado ${ }^{14}$ y los autos La siega, La puente del mundo y La locura por la honra, representaciones organizadas por la Junta Central del Tricentenario (nombrada por el Ministerio de Instrucción Pública y presidida por Ramón Menéndez Pidal) para ser ofrecidas públicamente en plazas madrileñas entorno a la fecha conmemorativa, el 27 de agosto. A estas habría que añadir también La gala de Medina o El caballero de Olmedo, refundición de Julio de Hoyos estrenada en Madrid en octubre de 1934, pero que continuó en gira por España a lo largo del 35. Nótese, además, que se ha incluido en el recuento $L a$ Dorotea, en una versión en verso pensada para su representación teatral del dramaturgo Eduardo Marquina, quien se basó en la novela de Lope para los dos primeros actos, pero que creó un tercero totalmente original que provocó cierta polémica y división de opiniones entre la crítica por la visión que ofrecía acerca del propio Lope, al que convertía en personaje de la obra y objeto de veneración ${ }^{15}$.

Por su parte, también en provincias aumenta notablemente la presencia de Lope: se han localizado catorce piezas, la mayoría de ellas estrenadas en Madrid previamente, con la excepción de la ya mencionada La esclava de su galán, cuya primera representación tuvo lugar en Toledo, el 28 de mayo, y La buena guarda y El castigo sin venganza, las dos piezas montadas y dirigidas por Juan Chabás y subvencionadas por la Junta del Tricentenario para ser llevadas por diversas ciudades del norte de España con motivo del aniversario. Además, la compañía Guerrero-Díaz de Mendoza recuperó de su repertorio sus antiguos montajes de El perro del hortelano y La Estrella de Sevilla, que acompañaron a La niña boba (representada en Madrid el 16 y 17 de marzo) en su estancia en Barcelona. Estos son, precisamente, de los pocos montajes que se reponen este año, junto con una representación de Las famosas as-

14 En realidad, la pieza no es de Lope, lo que provocó una pequeña polémica acerca de su elección.

15 Sobre la obra, puede consultarse también el artículo de Russo (2016). 
turianas y la de La moza de cántaro del Español, a cargo de Ricardo Calvo, que opta por la versión de primeros de siglo de Luceño, en lugar de la aplaudida de Rivas Cherif de 1930.

Por fortuna, el año del tricentenario favoreció la recuperación de algunas piezas desconocidas hasta entonces del Fénix, así como el abandono de la práctica de las refundiciones y la apuesta por una puesta en escena moderna. En este sentido, podemos destacar la elección de algunas piezas: por una parte, llama la atención la elección de un entremés y tres autos sacramentales para celebrar de forma pública la efeméride, totalmente desconocidos por parte del público y cuyo contenido (el de los autos, al menos) no haría de ellas las piezas más sencillas y amenas para un público popular, como notan algunos críticos en sus reseñas. Aunque por entonces estaba extendida la idea de la sencillez y naturalidad de los autos de Lope ${ }^{16}$, algunos autores (como Rodríguez-Solás, 2014, 177-182) han apuntado que, tras esta elección, se escondían intereses de tipo ideológico, que pretendían transmitir a la población una imagen eminentemente reaccionaria del Fénix. Sea como fuera, lo cierto es que a estas funciones (que se repitieron posteriormente por distintas ciudades españolas con mayor o menor éxito) acudió un número sorprendentemente alto de espectadores, quizás más atraídos por el festejo y el espectáculo que por las obras en sí, como observa Enrique Díez-Canedo (1935b) en un artículo de la época.

Por otra parte, destaca también el rescate del olvido de piezas hoy tan célebres como El caballero de Olmedo, consolidada ese mismo año por La Barraca, que la estrenaría en Santander el 22 de agosto, o El villano en su rincón, que Rivas Cherif escoge para el homenaje del Teatro Español a Lope. El director había propuesto al Ayuntamiento de Madrid una ambiciosa serie de actividades con motivo del centenario, pero, tras el silencio oficial, el homenaje se limitó a la representación de Fuente Ovejuna, El villano en su rincón y La dama boba, tres montajes que recuperaban

16 Ver por ejemplo el artículo de Escudero Baztán (2017), que estudia la representación de los tres autos durante el tricentenario. 
el texto original de Lope y que supusieron, probablemente, los actos más prestigiosos y de mayor calidad artística del tricentenario, siendo aplaudidos unánimemente desde periódicos de una y otra ideología. Esto último resulta importante porque, desde hacía años, la compañía del Español venía siendo habitual objeto de crítica por parte de la prensa más reaccionaria, a causa de la relación de su actriz principal, Margarita Xirgu, y su director artístico con Izquierda Republicana ${ }^{17}$. Por ello, hay que destacar que, aunque algunas cabeceras conservadoras evitan en la medida de lo posible elogiar en demasía los montajes del Español, e incluso mencionarlos siquiera, las reseñas que encontramos en ellas (cuando las encontramos) son siempre positivas, aunque comedidas, eso sí. Llama la atención, por ejemplo, que un diario como $A B C$ evite mencionar en todo momento el nombre de Rivas Cherif, responsable máximo del montaje y de la recuperación del texto original, que se presentaba al público de forma íntegra, sin apenas cortes y sin añadidos. La prensa más progresista, por su parte, no puede mostrarse más entusiasta ante los tres montajes, a los que dedica numerosos anuncios y extensas entradas en sus páginas, destacando la labor de la compañía Xirgu-Borrás hasta el punto de ser considerada "lo único integralmente digno y esplendoroso que se ha hecho en este año de indeclinable tributo al Fénix" (Espina, 1935).

Lo cierto es que los homenajes oficiales dejaron mucho que desear: la inestabilidad política (estamos en un año en el que hubo seis cambios de gobierno) provocó que los festejos se retrasasen y finalmente estuviesen caracterizados por la improvisación y cierto aire frío y pobre. Frente a ello, destacó la iniciativa privada y particular, independiente de órganos oficiales, dentro de la cual, en el terreno teatral, sobresalió el trabajo llevado a cabo por la compañía Xirgu-Borrás ${ }^{18}$. Entre otras muchas cuestiones que podrían men-

$17 \mathrm{Al}$ respecto, puede consultarse el completo estudio de Aguilera Sastre y Aznar Soler (2000), en especial su capítulo dedicado a la dirección del Español.

18 Junto a ellos, destacó también la calidad alcanzada por compañías de aficionados, como el Club Teatral Anfistora, que puso en escena una brillante versión de 
cionarse, la crítica alaba el buen hacer de Rivas Cherif como director en un sentido moderno, como declara Díez-Canedo (1935a) con relación a Fuente Ovejuna: "Aquí vemos lo que es una dirección escénica, una apreciación cabal del teatro como plástica; es decir, lo que más a menudo se encuentra a faltar en obras de más empeño que las quietas y comedidas producciones de ahora". En su opinión, el montaje había destacado por la enorme fuerza plástica y visual de algunas escenas, los magníficos efectos conseguidos por Sigfrido Burmann con sus decorados, la poderosa interpretación de la Xirgu, brillantemente acompañada por un numeroso grupo de actores, o la inclusión de músicas y danzas, para lo cual la compañía había sido asesorada por miembros del Centro de Estudios Históricos, los musicólogos Eduardo Martínez Torner, José Castro Escudero y Jesús Bal y Gay. Por todo ello declara que "pocas veces una adaptación ha sido lo que es esta [...] El camino está abierto, no hay más que seguirlo". Y parece que se siguió en las siguientes obras que se llevan a las tablas del Español, que destacan también por la buena acogida del público (un poco más frío en el caso de $E l$ villano en su rincón, a pesar de alcanzar las cuarenta y cinco representaciones). En el caso de La dama boba, en la versión que Federico García Lorca había estrenado un año antes en Buenos Aires ${ }^{19}$ y que devolvía la obra a su original tras años siendo representada a través de refundiciones que modificaban profundamente la pieza, la compañía quería despedirse con ella de su estancia en el Español: tras su representación en la Chopera del Retiro el 27 de agosto, en un festival organizado por el diario El Liberal al que asistieron más de cinco mil personas, el éxito de la comedia obligó a alargar su

Peribáñez, La Barraca, con Fuente Ovejuna y El caballero de Olmedo, o el Teatro Escuela de Arte, también dirigido por Rivas Cherif, que llegó a escenificar El acero de Madrid y La corona merecida antes de verse privado de su sede, el Teatro María Guerrero. Por toda la geografía española, se multiplicaron los grupos de aficionados y escuelas de actores que dedicaron a Lope una o más de sus obras; sobre ello puede consultarse Álvarez Álvarez (2019, 295-338), que recoge un total de cincuenta y nueve montajes de veintisiete obras lopescas.

19 Ver al respecto el imprescindible trabajo de Aguilera Sastre y Lizarraga Vizcarra (2008). 
estancia en el teatro madrileño hasta el 8 de septiembre, cuando Margarita Xirgu y Rivas Cherif partirían para Barcelona, dejando a Enrique Borrás al frente del Español, junto a Ricardo Calvo y Emilio Thuillier, sus nuevos concesionarios. Frente al éxito de público y de crítica que alcanzan estas tres piezas, contrasta el bajo número de representaciones y el poco espacio que ocupa en prensa la pieza que Calvo lleva al Español en homenaje a Lope antes de que termine el año: el hecho de que se trate de la reposición de una antigua refundición lo explicaría. Aunque las críticas a la pieza son en general positivas, alguna revela una dirección mediocre por parte de Calvo, que supondría un paso atrás en el Español tras el paso por él de Cipriano de Rivas Cherif.

La conmemoración lopesca significó una pequeña revolución para el teatro clásico en la época: algunos autores, como Melchor Fernández Almagro (1935), ponen su esperanza en que las celebraciones provocasen el tan deseado cambio en el plano cultural en el país:

El luminoso fantasma de Lope puede ser, a este respecto, un animador estupendo. [...] Si los clásicos se aposentan en los teatros indicados para recibirlos, y el pueblo español no pierde el contacto con Musas de tanto porte, tendremos que señalar los pasados días de agosto con trazo vigoroso y brillante, puesto que marcará el renacimiento de nuestro Teatro.

Pero no podemos saber si tales esperanzas se harían realidad, pues el estallido de la Guerra Civil supuso un triste parón para las artes escénicas en el país, que se vio privado de algunas de las figuras que más estaban haciendo por él, como los propios Margarita Xirgu, Rivas Cherif o García Lorca. Como sostiene Cienfuegos Antelo (2016, 252), la labor de estos con los clásicos, que tuvo felices frutos durante el tricentenario, supuso un punto de inflexión y se revela como uno de los pilares fundamentales que sostienen el gran momento que hoy en día viven nuestros autores barrocos. 


\section{Después del tricentenario: Fuente Ovejuna y la Guerra Civil}

La importancia de Fuente Ovejuna en 1935 es fundamental: no solo se convierte en la pieza de Lope más representada en el Español (siendo la segunda obra con más funciones de la compañía, tan solo detrás de Yerma, el gran éxito de la temporada), sino que es la obra más representada en toda España, siendo la más elegida por parte de los grupos de aficionados, así como en el extranjero. Afortunadamente, gracias a la prensa, conocemos bien cómo fue el montaje del Español y podemos asegurar que estaba ausente de él cualquier lectura política que la ligara con la actualidad (más allá de la que cualquiera pueda hacer de la obra de Lope), frente a lo ocurrido tres años antes con la versión de López Alarcón.

Poco después, una vez estallada la guerra, el grupo de teatro dirigido por Luis Mussot, miembro del partido comunista y secretario de Organización de Espectáculos Públicos, la escoge para ser representada, parcialmente, dentro de un festival compuesto por diversas escenas, ballets y piezas breves. La obra se había cargado para entonces de un peso ideológico e incluso político que la conectaba directamente con la actualidad española. Aunque en el estudio de Luis M. González (1996) se recoge que la pieza se habría representado entre el 16 de septiembre del 36 y el 13 de enero del 37, con un total de diez funciones, en nuestro repaso de las carteleras madrileñas hemos localizado que su primera representación tuvo lugar el 11 de septiembre, cuando es anunciado un festival en el Teatro Popular de Madrid (antiguo Fontalba, en la Gran Vía) en beneficio del Socorro Rojo Internacional, compuesto por ballets de Verdi, Weber, Paderewsky y Strauss, escenas del tercer acto de Fuente Ovejuna (las de la sublevación del pueblo contra el comendador) y el monólogo de Segismundo del primer acto de La vida es sueño. La representación también incluía la escenificación de un poema humorístico de Rafael Alberti, "El Gil-Gil", pieza breve de 1934 que se burlaba de la figura de José María Gil-Robles, dirigente de la CEDA, y que parte, precisamente, de un villancico de Lope de Vega, “ $\mathrm{OOh}$, qué bien baila Gil!". La función se repitió en días posteriores has- 
ta el 13 de octubre, con un total de veintiocho representaciones: en todas se mantienen las escenas de Fuente Ovejuna, aunque el resto del programa se modifica un poco, incluyendo la actuación de diversas cantantes, las recitaciones de actores como Catalina Bárcena o Arturo de la Riva, o la escenificación de obras con un claro componente político, como ¡No pasarán!, del propio Luis Mussot, o El secreto, de Ramón J. Sender, perfecto ejemplo de teatro revolucionario de agitación y propaganda (Aznar Soler, 2001). Está claro entonces que la elección de la obra lopesca responde a motivos políticos, siendo representada no íntegramente, sino escogiendo un momento muy significativo de la comedia, y dentro de un amplio programa de propaganda. No mucho tiempo después, en enero de 1938, la pieza volverá a ser representada, esta vez íntegramente y en una versión de Diego San José.

La comedia cobra especial popularidad durante la Guerra Civil $^{20}$, como ejemplo del teatro que debía ser ofrecido al público y a los combatientes, digno del sacrificio de estos, frente a otro tipo de obras, de contenido frívolo, que empobrecían el panorama teatral (véase Doménech Rico, 2019, 94-96). En este sentido, entre finales de 1937 y principios de 1938, coinciden en los escenarios madrileños dos piezas clásicas que conocen un terrible éxito y que incorporan, además, novedades técnicas y escénicas: en la Zarzuela, la versión de Numancia preparada por Rafael Alberti, que alcanza las setenta representaciones, y la Fuente Ovejuna de San José, que bate récords con ciento quince representaciones en el Español, entre el 1 de enero y el 30 de abril de 1938.

20 Fuera de Madrid, la versión de García Lorca es ofrecida en agosto del 38 en el Teatro Municipal de Gerona por un grupo de aficionados dirigidos por Pío Fernández Muriedas (Marrast, 1978, 189), y la de Diego San José, que tratamos a continuación, se representó en julio del mismo año en Barcelona y, en diciembre, en el Teatro Principal de Valencia por parte de la compañía de Salvador Soler Marí y Milagros Leal. Además, la pieza abre la colección "Pequeña Biblioteca Teatral" de la Editorial Signo. La revista Claridad, órgano oficial de UGT, alaba el prólogo de Antonio Olivares, "ajustado al profundo significado de la obra de Lope" (I. R. M., 1937), que se centra en su carga revolucionaria y popular (Doménech Rico, 2019, 96), y advierte de la presencia de "pequeñas modificaciones que no alteran el carácter fundamental de la obra y que han sido aceptadas en recientes revisiones". 
En su estudio del manuscrito conservado por la familia del escritor, Doménech Rico (2019) observa que esta versión respeta el original lopiano, manteniendo las dos acciones y la estructura general de la obra, con algún corte en los diálogos y suprimiendo alguna escena o secuencia (sobre todo en lo que se refiere a la acción de gira alrededor de la guerra), con el propósito de aportar mayor fluidez a la pieza. A pesar de este respeto hacia el original, el escritor no se privó de aportar algún añadido a la obra, que modifica levemente la pieza, como cuando Frondoso se enfrenta al comendador, confiriendo al campesino una personalidad más heroica y arrojada, o en el parlamento de Esteban en el tercer acto, que moderniza su mensaje:

Que quien quiere esclavizar

al pueblo contra la ley,

aunque sea el mesmo rey,

con la vida ha de pagar.

Pero son sobre todo las décimas que ahora cerraban la obra, en boca de Frondoso, las que más actualizan la pieza y la propia persona de Lope:

Lope, poeta genial,

de imperecedera fama,

tres siglos ha que este drama

hizo con pluma inmortal.

Su espíritu liberal,

impregnado en rebeldía,

quiso con franca hidalguía

mostrar al pueblo, aherrojado,

cómo se rompe el odiado

yugo de la tiranía.

Pues que bien lo has aprendido, derramando heroicamente 
tu sangre, ipueblo valiente!

al ser tu suelo invadido

por tiranos, yo te pido

con hondísima emoción

salida del corazón,

y en nombre del triunfo nuestro,

que no olvidéis al Maestro

que te enseñó la lección.

La prensa del Madrid republicano aplaude la nueva adaptación. Se muestran favorables a la "exacta refundición" de San José (Ojeda, 1938) y a la dirección inteligente de Manuel González, aunque no dejan de recordar la versión de Rivas Cherif y Margarita Xirgu, que había quedado para los anales de la historia del Español. En este sentido, desde $A B C$, SAM (1938), seudónimo de Serafín Adame, echa en falta el vigor y el dramatismo de antiguas versiones, especialmente en momentos como la arenga de Laurencia en el tercer acto, aunque alaba la "mano respetuosa" del adaptador. También Ojeda, desde La Libertad, ensalza los magníficos decorados de Ripoll y Guerra y la refundición "perfecta", hecha con mesura, respeto y cuidado, y reconoce el mérito del director: "Colocaciones, movimientos de figuras y coros, bailes, canciones, luces, y el tono, en fin, general de una interpretación que él [Manuel González] encabeza con la dignidad y el acierto acostumbrados". El mismo se alegra de poder contemplar en los escenarios madrileños la coincidencia de obras de Lope, Cervantes, Galdós o Benavente, que consolaba del habitual panorama desazonador de la cartelera. En cuanto a la adición de los versos finales, SAM los considera "irreprochables de forma y fondo", y Ojeda advierte que San José quiso colocarlos al final de la obra para evitar malinterpretaciones y que nadie pensara que formaban parte del original: “La alusión 'actualizada' de la misma está ya al final, cuando la comedia ha terminado. Así nadie puede llamarse a engaño".

Con motivo del séptimo aniversario de la proclamación de la República, el Frente Popular seleccionó la pieza para ser repre- 
sentada en un pase especial, la mañana del domingo 17 de abril, con el propósito de facilitar la asistencia de obreros y trabajadores. En su presentación, Régulo Martínez destacó la actualidad que el drama adquiría en las circunstancias del momento, significación que también subrayan desde $A B C$ (19-4-1938), para el cual la obra se alzaba como "símbolo de nuestra lucha a muerte con el fascismo". Su elección por parte del gobierno republicano para esta conmemoración, así como las décimas que San José añadió al final de la obra, pesaron de forma determinante en el futuro del escritor: condenado a muerte poco después del final de la guerra, entre las causas que justificaban tal pena se encontraba su versión de Fuente Ovejuna, que era interpretada como una incitación al pueblo a la rebeldía, a pesar de la fidelidad con la que había seguido al Fénix (véase Doménech Rico, 2019, 106-109). Finalmente, la pena se conmutó por treinta años de reclusión, gracias a la intervención de un antiguo compañero de tertulia, el general Millán Astray.

\section{Recapitulación: Lope de Vega en los años 30}

A lo largo de la década de 1930, el teatro clásico conoció un cambio en su concepción y recepción por parte del público y la crítica, que pudo ver por fin respuestas concretas a las reivindicaciones que venía haciendo desde la década anterior, en buena parte materializadas en los montajes de piezas lopescas. Poco a poco, tímidamente, las innovaciones escénicas y el respeto al texto y al autor fueron ganando terreno, recobrando dignidad y valor artístico. El momento de esplendor tuvo lugar en 1935, con motivo del tercer centenario de la muerte de Lope de Vega, momento que se supo aprovechar para recuperar algunas obras del Fénix y para ofrecer innovadores montajes a un público que demostró saber responder al arte de calidad cuando se le ofrecía. El parón que supuso la Guerra Civil en todos los sentidos nos deja con la incógnita de qué habría podido suceder si los responsables de aquellos montajes hubiesen podido continuar con su labor artística. Pero las circunstancias 
sociopolíticas se impusieron en aquellos momentos y Fuente Ovejuna, que llevaba una larga temporada cargándose de una fuerte significación ideológica, se impone durante la contienda, aunque no por ello se olvida el valor artístico y la parte espectacular de la obra, que son alabados en la puesta en escena del Español de 1938.

\section{Referencias bibliográficas}

$A B C$ 19-4-1938: 7. "Español: Una extraordinaria representación de Fuenteovejuna".

Aguilera Sastre, J. e I. Lizarraga Vizcarra (2008) Federico García Lorca y el teatro clásico: la versión escénica de La dama boba, Logroño, Universidad de La Rioja.

Aguilera Sastre, J. y M. Aznar Soler (2000) Cipriano de Rivas Cherif y el teatro español de su época (1891-1967), Madrid, Asociación de Directores de Escena de España.

Ahora 31-1-1932: 42. "Estreno, en el Español, de una refundición de Fuenteovejuna".

Alsina, J. (1931) “Español - Presentación de la compañía Guerrero-Díaz de Mendoza. El perro del hortelano", La Nación [Madrid] 28-2-1931, 11.

Álvarez Álvarez, M. (2019) Recepción crítica y utilización de la figura y la obra de Lope de Vega en el tricentenario de su muerte: el papel de la prensa periódica, tesis de doctorado, Universidad de Oviedo.

Araujo-Costa, L. (1930) “Español - Reposición de la comedia famosa, restaurada en la versión original de Lope de Vega, y refundida escénicamente en diez cuadros, dispuestos en cuatro jornadas por C. Rivas Cherif, La moza de cántaro", La Época [Madrid] 14-5-1930, 1.

Araujo-Costa, L. (1931) “Español - Presentación de la compañía Guerrero-Mendoza con la comedia en tres actos de Lope de Vega, refundida por Manuel y Antonio Machado, El perro del hortelano", La Época [Madrid] 28-2-1931, 1. 
Araujo-Costa, L. (1932) “Español - Reposición de la comedia de Lope de Vega, refundida por Enrique López Alarcón, Fuenteovejuna", La Época [Madrid] 1-2-1932, 1.

Aznar Soler, M. (2001) "La literatura dramática de Ramón J. Sender: de El secreto (1935) a Comedia del diantre (1969)", en Dueñas Lorente, J. D. (ed.), Sender y su tiempo. Crónica de un siglo. Actas del II Congreso sobre Ramón J. Sender: Huesca, 27-31 de marzo de 2001, Huesca, Instituto de Estudios Altoaragoneses, 55-82.

Cienfuegos Antelo, G. (2016) “'De tus mudanzas me admiro': La dama boba de Lope desde el siglo XIX", en Serés, G. y Vega García-Luengos, G. (dirs.), Menéndez Pelayo y Lope de Vega, Santander, Universidad de Cantabria, 231-257.

Díez-Canedo, E. (1931) “Español - Compañía Guerrero-Díaz de Mendoza. El perro del hortelano, de Lope de Vega, adaptación de M. A. Machado", El Sol [Madrid] 28-2-1931, 6.

Díez-Canedo, E. (1932) “Español - Fuenteovejuna, de Lope de Vega; adaptación de Enrique López Alarcón”, El Sol [Madrid] 311-1932, 12.

Díez-Canedo, E. (1935a) “Conmemoración de Lope de Vega y representación de Fuenteovejuna", La Voz [Madrid] 25-3-1935, 3.

Díez-Canedo, E. (1935b) “Lope, al cabo de tres siglos", El Sol [Madrid] 28-8-1935, 1.

Doménech Rico, F. (2019) “Fuente Ovejuna en la Guerra Civil. La versión de Diego San José", en Huerta Calvo, J. (ed.), Fuente Ovejuna (1619-2019). Pervivencia de un mito universal, Nueva York, IDEA, 93-109.

Dougherty, D. (1983) “El legado vanguardista de Tirso de Molina", en $V$ jornadas de teatro clásico español. (El trabajo con los clásicos en el teatro contemporáneo). Almagro, 1982, vol. 2, Madrid, Ministerio de Cultura, 13-28.

Dougherty, D. (1984) "Talía convulsa: la crisis teatral de los años 20", en Dos ensayos sobre el teatro español de los veinte, Murcia, Universidad de Murcia, 85-157. 
Dougherty, D. (2013) "Fuente Ovejuna en clave republicana. La refundición de Enrique López Alarcón (1932)", Anales de la Literatura Española Contemporánea, 38.1-2, 127-147.

Dougherty, D. y M. F. Vilches de Frutos (1990) La escena madrileña entre 1918 y 1926. Análisis y documentación, Madrid, Fundamentos.

Dougherty, D. y M. F. Vilches de Frutos (1997) La escena madrileña entre 1926 y 1931. Un lustro de transición, Madrid, Fundamentos.

Escudero Baztán, J. M. (2017) “Un hito previo al estudio del género sacramental en la posguerra española: Los autos de Lope de Vega en la conmemoración de su tricentenario", Bulletin Hispanique, 119.1 (juin), 133-142.

Espina, A. (1932) "Reposición de Fuenteovejuna", Luz [Madrid] 1-2-1932, 6.

Espina, A. (1935) “Español - Semana final del homenaje a Lope. Reposición de La moza del cántaro", El Sol [Madrid] 24-121935, 2.

Fernández Almagro, M. (1932) «El sábado de representó en el Español Fuenteovejuna - Consideraciones acerca de la refundición de López Alarcón", La Voz [Madrid] 1-2-1932, 3.

Fernández Almagro, M. (1935) “Después del centenario de Lope", La Prensa [Gijón] 10-9-1935, 5.

Florit Durán, F. (2000) “La recepción de Lope en 1935: ideología y literatura", Anuario Lope de Vega, 6, 107-124.

G. de Candamo, B. (1932) “En el Teatro Español - Fuente Ovejuna, de Lope de Vega", El Imparcial [Madrid] 31-1-1932, 1.

Gago Rodó, A. (1997) "1903, Manuel Bueno y Valle-Inclán adaptan Fuente Ovejuna", en Iglesias Feijoo, L., Santos Zas, M., Serrano Alonso, J. y Juan Bolufer, A. de (eds.), Valle-Inclán y el Fin de Siglo. Congreso Internacional. Santiago de Compostela, 23-28 de octubre de 1995, Santiago de Compostela, Universidad de Santiago de Compostela, 447-474.

García Santo-Tomás, E. (2000) La creación del Fénix. Recepción crítica y formación canónica del teatro de Lope de Vega, Madrid, Gredos. 
Gil Fombellida, M. C. (2003) Rivas Cherif, Margarita Xirgu y el teatro de la II República, Madrid, Fundamentos.

GonzÁlez, L. M. (1996) La escena madrileña durante la II República (1931-1939). Teatro. Revista de Estudios Teatrales, 9-10.

González Blanch, P. (2004) El teatro en Segovia (1918-1936), tesis de doctorado, UNED.

GonzÁlez Olmedilla, J. (1931) “Inauguración de temporada en el Español por la compañía María Guerrero-Fernando Díaz de Mendoza", Heraldo de Madrid 28-2-1931, 5.

GonzÁlez Olmedilla, J. (1932) “Borrás, en el Español, repone con éxito Fuenteovejuna, de Lope de Vega, en la refundición de Enrique López Alarcón", Heraldo de Madrid 1-2-1932, 5.

I. R. M. (1937) “Libros”, Claridad [Madrid] 2-12-1937, 6.

Iglesias, M. A. (1999) “Cipriano Rivas Cherif y Margarita Xirgu en el tricentenario de Lope de Vega: datos para la historia del teatro español", Anuario Lope de Vega, 5, 83-118.

Iglesias, M. A. (2002) "Peribáñez y el comendador de Ocaña en la versión de Federico García Lorca y el Club Teatral Anfistora: noticias y recepción de la obra en la prensa madrileña", Boletín de la Fundación Federico García Lorca, 32, 33-45.

Kirschner, T. J. (1977) "Sobrevivencia de una comedia: historia de la difusión de Fuenteovejuna", Revista Canadiense de Estudios Hispánicos, 1, 255-271.

Lanz, J. J. (2017) “Blas de Otero homenajea a Federico García Lorca. Texto y contexto de 'Recuerdo que en Bilbao...': 19361976”, Ancia. Revista de la Fundación Blas de Otero, 10, 6-26.

Mancebo Salvador, Y. (2018) "El castigo sin venganza, a la conquista del repertorio", Anuario Lope de Vega. Texto, literatura, cultura, 24, 200-242. DOI: https://doi.org/10.5565/rev/anuariolopedevega. 244

Marrast, R. (1978) El teatre durant la Guerra Civil española, Barcelona, Institut del Teatre.

Masip, P. (1931) “En el Español se estrena una refundición de El perro del hortelano", Ahora [Madrid] 28-2-1931, 23. 
Menéndez Pelayo, M. (1949) Estudios sobre el teatro de Lope de Vega, V. Crónicas y leyendas dramáticas de España, Santander, CSIC.

Miquis, A. (1930) "Semana teatral - La moza de cántaro - Pitusa", La Esfera [Madrid] 24-5-1930, 5.

Miquis, A. (1931). "En torno al reciente estreno de El hombre deshabitado y a la reposición de El perro del hortelano". Nuevo Mundo [Madrid] 13-3-1931, 22-23.

Miquis, A. (1932). "Quincena Teatral”, Nuevo Mundo [Madrid] 5-2-1932, 25.

Mori, A. (1930) “Español - La moza de cántaro, refundición de Rivas Cherif", El Liberal [Madrid] 14-5-1930, 5.

Ochando Madrigal, E. (1998) La vida escénica en Albacete (1924-1936), tesis de doctorado, UNED.

OJedA, J. (1938) “Español - Fuenteovejuna, del inmortal Lope de Vega, a través de una exacta refundición realizada por Diego San José", La Libertad [Madrid] 11-1-1938, 2.

Oliva, C. (2011) "El Arte de Lope en la escena española del siglo XX", RILCE. Revista de Filología Hispánica, 27.1, 161-173.

Paredes, [F.] (1931) "Fuencarral - El castigo sin venganza", La Tierra [Madrid], 17-12-1931, 3.

Paredes, F. (1932) “En el Español - Fuente Ovejuna, de Lope de Vega, refundida por Enrique López Alarcón”, La Tierra [Madrid] 1-2-1932, 3.

Pedraza Jiménez, F. B. (2002) "La dama boba y Peribáñez: las huellas en el tiempo", Cuadernos de Teatro Clásico, 17, 13-40.

Rivas Cherif, C. (1991) Cómo hacer teatro: apuntes de orientación profesional en las artes y oficios del teatro español, Valencia, Pre-Textos.

Rodríguez-Solás, D. (2014) Teatros nacionales republicanos. La Segunda República y el teatro clásico español, Madrid, Iberoamericana-Vervuert.

Romera Castillo, J. (2012) “Obras de Lope de Vega en algunas carteleras de provincias españolas (1900-1936)", en Botta, P. (coord.) y Vaccari, D. (ed.), Rumbos del hispanismo en el umbral del Cincuentenario de la AIH, vol. 4, Roma, Bagatto Libri, 377-385. 
Romero Ferrer, A. (1998) “Clásicos después de los clásicos: las refundiciones dramáticas de Manuel y Antonio Machado", en J. Martín Castellanos, J., Velázquez Basanta, F. y Bustamante Costa, J. (eds.), Estudios de la Universidad de Cádiz ofrecidos a la memoria profesor Braulio Justel Calabozo, Cádiz, Universidad de Cádiz, 381-388.

Russo, A. (2016) “En el tricentenario de Lope de Vega: La Dorotea de Eduardo Marquina", Anuario Lope de Vega. Texto, literatura, cultura, 22, 238-260. DOI: https://doi.org/10.5565/rev/anuariolopedevega.156

SAM (1938) "Español: Fuente Ovejuna", ABC [Madrid] 8-11938,6 .

Somalo Fernández, M. Á. (2004) El teatro en Logroño (19011950), tesis de doctorado, Universidad de La Rioja.

Un Espectador Sencillo (1932) "Español: Fuente Ovejuna", El Siglo Futuro [Madrid] 1-2-132, 2.

Vázquez Honrubia, A. (2004) Teatro, cine y otros espectáculos en Llanes (Asturias): 1923-1938, tesis de doctorado, UNED.

Weiner, J. (1982) “Lope de Vega's Fuenteovejuna under Tsars, Commissars and the Second Spanish Republic (1931-1939)", Annali: Sezione Romanza. Istituto Universitario Orientale, 24.1, 167-223.

Zamora Muñoz, M. J. (2015) El tricentenario de Lope de Vega. Una conmemoración cultural en la España de 1935, tesis de doctorado, Universidad Rey Juan Carlos. https://burjcdigital.urjc.es/ handle/10115/15088 (6/2/2021).

Zamora Muñoz, M. J. (2019) "El tricentenario de Lope de Vega en la cartelera madrileña", Signa. Revista de la Asociación Española de Semiótica, 28, 1571-1599. DOI: https://doi.org/10.5944/ signa.vol28.2019.25131 


\section{APÉNDICE}

Tabla 1: Obras de Lope de Vega en la cartelera madrileña, 1930-1939, compañías profesionales.

\begin{tabular}{|c|c|c|c|c|c|}
\hline Título & $\begin{array}{c}\text { Fecha } \\
\text { estreno }\end{array}$ & $\begin{array}{l}\text { N. }{ }^{\circ} \\
\text { repr. }\end{array}$ & Compañía & Director & Lugar \\
\hline $\begin{array}{l}\text { La Estrella de } \\
\text { Sevilla }\left({ }^{*}\right)^{21}\end{array}$ & 19/3/1930 & 1 & $\begin{array}{l}\text { Cía. Dramática } \\
\text { Española } \\
\text { Guerrero-Díaz } \\
\text { de Mendoza } \\
\end{array}$ & $\begin{array}{l}\text { Fernando } \\
\text { Díaz de } \\
\text { Mendoza y } \\
\text { Guerrero } \\
\end{array}$ & T. Español \\
\hline $\begin{array}{l}\text { La moza de } \\
\text { cántaro }\end{array}$ & $13 / 5 / 1930$ & 9 & $\begin{array}{l}\text { Cía. Clásica } \\
\text { Moderna Barrón- } \\
\text { Rivas Cherif }\end{array}$ & $\begin{array}{l}\text { C. de Rivas } \\
\text { Cherif }\end{array}$ & T. Español \\
\hline $\begin{array}{l}\text { El perro del } \\
\text { hortelano }\end{array}$ & $27 / 2 / 1931$ & 27 & $\begin{array}{l}\text { Cía. Dramática } \\
\text { Española } \\
\text { Guerrero-Díaz } \\
\text { de Mendoza } \\
\end{array}$ & $\begin{array}{l}\text { Fernando } \\
\text { Díaz de } \\
\text { Mendoza y } \\
\text { Guerrero } \\
\end{array}$ & T. Español \\
\hline $\begin{array}{l}\text { La niña boba o } \\
\text { Buen maestro es el } \\
\text { amor }\left(^{*}\right)\end{array}$ & 25/3/1931 & 1 & $\begin{array}{l}\text { Cía. Dramática } \\
\text { Española } \\
\text { Guerrero-Díaz } \\
\text { de Mendoza } \\
\end{array}$ & $\begin{array}{l}\text { Fernando } \\
\text { Díaz de } \\
\text { Mendoza y } \\
\text { Guerrero } \\
\end{array}$ & T. Español \\
\hline $\begin{array}{l}\text { El castigo sin } \\
\text { venganza }\left(^{*}\right)\end{array}$ & $16 / 12 / 1931$ & 1 & Ricardo Calvo & \begin{tabular}{|l|} 
Ricardo \\
Calvo \\
\end{tabular} & T. Fuencarral \\
\hline Fuente Ovejuna & $30 / 1 / 1932$ & 23 & Enrique Borrás & $\begin{array}{l}\text { Enrique } \\
\text { Borrás }\end{array}$ & T. Español \\
\hline $\begin{array}{l}\text { La gala de Medina } \\
\text { o El caballero de } \\
\text { Olmedo }\end{array}$ & 18/10/1934 & 22 & Melià-Cibrián & $\begin{array}{l}\text { Benito } \\
\text { Cibrián }\end{array}$ & T. Español \\
\hline La Dorotea & 23/1/1935 & 49 & Carmen Díaz & $\begin{array}{l}\text { Eduardo } \\
\text { Marqina }\end{array}$ & T. Cómico \\
\hline La niña boba $\left(^{*}\right)$ & 16/3/1935 & 3 & $\begin{array}{l}\text { Cía. Dramática } \\
\text { Española } \\
\text { Guerrero-Díaz } \\
\text { de Mendoza } \\
\end{array}$ & $\begin{array}{l}\text { Fernando } \\
\text { Díaz de } \\
\text { Mendoza y } \\
\text { Guerrero } \\
\end{array}$ & T. Fontalba \\
\hline \multirow[b]{2}{*}{ Fuente Ovejuna } & 23/3/1935 & 60 & \multirow[b]{2}{*}{ Xirgu-Borrás } & \multirow{2}{*}{$\begin{array}{l}\text { C. de Rivas } \\
\text { Cherif }\end{array}$} & T. Español \\
\hline & 1/9/1935 & 1 & & & $\begin{array}{c}\text { Chopera del } \\
\text { Retiro }\end{array}$ \\
\hline
\end{tabular}

21 Con asterisco se marca la reposición de montajes. 


\begin{tabular}{|c|c|c|c|c|c|}
\hline $\begin{array}{l}\text { La esclava de su } \\
\text { galán }\end{array}$ & $30 / 5 / 1935$ & 1 & $\begin{array}{l}\text { Carlos Martínez } \\
\text { Baena }\end{array}$ & \begin{tabular}{|l} 
Rafael \\
Marquina y \\
Carlos M. \\
Baena
\end{tabular} & $\begin{array}{l}\text { Círculo de } \\
\text { Bellas Artes }\end{array}$ \\
\hline $\begin{array}{l}\text { San Isidro, } \\
\text { labrador }\end{array}$ & $31 / 5 / 1935$ & 10 & $\begin{array}{l}\text { Díaz de Artigas- } \\
\text { Collado }\end{array}$ & $\begin{array}{l}\text { Manuel } \\
\text { Collado }\end{array}$ & T. Eslava \\
\hline \multirow{2}{*}{$\begin{array}{l}\text { El villano en su } \\
\text { rincón }\end{array}$} & $1 / 6 / 1935$ & \multirow{2}{*}{45} & \multirow{2}{*}{ Xirgu-Borrás } & \multirow{2}{*}{$\begin{array}{l}\text { C. de Rivas } \\
\text { Cherif }\end{array}$} & \multirow{2}{*}{ T. Español } \\
\hline & $4 / 9 / 1935$ & & & & \\
\hline \multirow[b]{2}{*}{ El degollado } & 24/8/1935 & 1 & \multirow[b]{2}{*}{ José Monteagudo } & \multirow[b]{2}{*}{$\begin{array}{l}\text { José } \\
\text { Monteagudo }\end{array}$} & $\begin{array}{l}\text { Pl. Conde de } \\
\text { Miranda }\end{array}$ \\
\hline & 1/9/1935 & 1 & & & \begin{tabular}{|c|} 
C/ Raimundo \\
Fdez. \\
Villaverde \\
(Cuatro \\
Caminos) \\
\end{tabular} \\
\hline \multirow[b]{2}{*}{ La siega } & 25/8/1935 & 1 & \multirow[b]{2}{*}{ José Monteagudo } & \multirow[b]{2}{*}{$\begin{array}{l}\text { José } \\
\text { Monteagudo }\end{array}$} & $\begin{array}{c}\text { Pl. de las } \\
\text { Comendadoras }\end{array}$ \\
\hline & 1/9/1935 & 1 & & & $\begin{array}{c}\text { C/ Raimundo } \\
\text { Fdez. } \\
\text { Villaverde } \\
\text { (Cuatro } \\
\text { Caminos) }\end{array}$ \\
\hline $\begin{array}{l}\text { La puente del } \\
\text { mundo }\end{array}$ & 26/8/1935 & 1 & José Monteagudo & \begin{tabular}{|l|} 
José \\
Monteagudo
\end{tabular} & \begin{tabular}{|c|}
$\begin{array}{c}\text { Pl. Marqués de } \\
\text { Comillas }\end{array}$ \\
\end{tabular} \\
\hline La dama boba & 27/8/1935 & 22 & Xirgu-Borrás & $\begin{array}{l}\text { C. de Rivas } \\
\text { Cherif }\end{array}$ & $\begin{array}{l}\text { Chopera del } \\
\text { Retiro / T. } \\
\text { Español }\end{array}$ \\
\hline \multirow{2}{*}{$\begin{array}{l}\text { La locura por la } \\
\text { honra (auto) }\end{array}$} & 30/8/1935 & 1 & \multirow[b]{2}{*}{ José Monteagudo } & \multirow{2}{*}{$\begin{array}{l}\text { José } \\
\text { Monteagudo }\end{array}$} & $\begin{array}{c}\text { Pl. San } \\
\text { Francisco }\end{array}$ \\
\hline & 4/9/1935 & 1 & & & $\begin{array}{c}\text { Avda. de la } \\
\text { antigua plaza } \\
\text { de toros }\end{array}$ \\
\hline $\begin{array}{l}\text { Las famosas } \\
\text { asturianas }\left(^{*}\right)\end{array}$ & 28/10/1935 & 1 & $\begin{array}{l}\text { Sociedad } \\
\text { Artística Muñoz } \\
\text { Seca }\end{array}$ & $\begin{array}{l}\text { Santos } \\
\text { Moreno }\end{array}$ & T. Comedia \\
\hline $\begin{array}{l}\text { La moza de } \\
\text { cántaro }(*)\end{array}$ & 21/12/1935 & 6 & Calvo-Borrás & $\begin{array}{l}\text { Ricardo } \\
\text { Calvo }\end{array}$ & T. Español \\
\hline Fuente Ovejuna & $11 / 9 / 1936$ & 28 & Teatro Popular & Luis Mussot & T. Popular \\
\hline Fuente Ovejuna & $7 / 1 / 1938$ & 115 & \begin{tabular}{|l|} 
Manuel \\
González
\end{tabular} & \begin{tabular}{|l|} 
Manuel \\
González
\end{tabular} & T. Español \\
\hline
\end{tabular}


Tabla 2: Obras de Lope de Vega representadas en el resto de España, 1930-1939, compañías profesionales.

\begin{tabular}{|c|c|c|c|c|c|}
\hline Título & Fecha & $\begin{array}{l}\text { N. }{ }^{0} \\
\text { repr. }\end{array}$ & Compañía & Director & Lugar \\
\hline $\begin{array}{l}\text { La Estrella de } \\
\text { Sevilla }\left(^{*}\right)\end{array}$ & $1 / 1 / 1930$ & - & $\begin{array}{l}\text { C. D. E. } \\
\text { Guerrero- } \\
\text { Díaz de } \\
\text { Mendoza }\end{array}$ & $\begin{array}{l}\text { Fernando Díaz } \\
\text { de Mendoza y } \\
\text { Guerrero }\end{array}$ & Albacete \\
\hline $\begin{array}{l}\text { La moza de } \\
\text { cántaro }\end{array}$ & 18/2/1930 & 1 & $\begin{array}{l}\text { Cía. Clásica } \\
\text { Moderna } \\
\text { Barrón-Rivas } \\
\text { Cherif }\end{array}$ & $\begin{array}{l}\text { C. de Rivas } \\
\text { Cherif }\end{array}$ & $\begin{array}{l}\text { T. Juan Bravo, } \\
\text { Segovia }\end{array}$ \\
\hline $\begin{array}{l}\text { La niña boba o } \\
\text { Buen maestro es } \\
\text { el amor }\left(^{*}\right)\end{array}$ & $14 / 2 / 1931$ & - & $\begin{array}{l}\text { C. D. E. } \\
\text { Guerrero- } \\
\text { Díaz de } \\
\text { Mendoza }\end{array}$ & $\begin{array}{l}\text { Fernando Díaz } \\
\text { de Mendoza y } \\
\text { Guerrero }\end{array}$ & T. Circo, Albacete \\
\hline $\begin{array}{l}\text { El perro del } \\
\text { hortelano }\end{array}$ & 18/2/1931 & - & $\begin{array}{l}\text { C. D. E. } \\
\text { Guerrero- } \\
\text { Díaz de } \\
\text { Mendoza }\end{array}$ & $\begin{array}{l}\text { Fernando Díaz } \\
\text { de Mendoza y } \\
\text { Guerrero }\end{array}$ & T. Circo, Albacete \\
\hline \multirow{2}{*}{$\begin{array}{l}\text { La gala de } \\
\text { Medina o El } \\
\text { caballero de } \\
\text { Olmedo }\end{array}$} & $1 / 1 / 1935$ & - & \multirow{2}{*}{$\begin{array}{l}\text { Melià- } \\
\text { Cibrián }\end{array}$} & \multirow{2}{*}{ Benito Cibrián } & Zaragoza \\
\hline & 18/1/1935 & 17 & & & $\begin{array}{l}\text { T. Novedades, } \\
\text { Barcelona } \\
\end{array}$ \\
\hline \multirow{3}{*}{ La niña boba $\left(^{*}\right)$} & 18/5/1935 & 2 & \multirow{3}{*}{$\begin{array}{l}\text { C. D. E. } \\
\text { Guerrero- } \\
\text { Díaz de } \\
\text { Mendoza }\end{array}$} & \multirow{3}{*}{$\begin{array}{l}\text { Fernando Díaz } \\
\text { de Mendoza y } \\
\text { Guerrero }\end{array}$} & T. Dindurra, Gijón \\
\hline & 27/8/1935 & 2 & & & $\begin{array}{c}\text { Pueblo Español, } \\
\text { Montjuic, } \\
\text { Barcelona }\end{array}$ \\
\hline & $15 / 10 / 1935$ & 2 & & & $\begin{array}{c}\text { T. Poliorama, } \\
\text { Barcelona }\end{array}$ \\
\hline \multirow{5}{*}{$\begin{array}{l}\text { La esclava de su } \\
\text { galán }\end{array}$} & 28/5/1935 & - & \multirow{5}{*}{$\begin{array}{l}\text { Carlos } \\
\text { Martínez } \\
\text { Baena }\end{array}$} & \multirow{5}{*}{$\begin{array}{l}\text { Rafael } \\
\text { Marquina y } \\
\text { Carlos M. } \\
\text { Baena }\end{array}$} & T. Rojas, Toledo \\
\hline & $5 / 6 / 1935$ & 2 & & & $\begin{array}{l}\text { T. Juan Bravo, } \\
\text { Segovia }\end{array}$ \\
\hline & $7 / 6 / 1935$ & - & & & $\begin{array}{c}\text { T. Cervantes, } \\
\text { Alcalá de Henares }\end{array}$ \\
\hline & Junio 1935 & - & & & $\begin{array}{c}\text { Madridejos } \\
\text { (Toledo) }\end{array}$ \\
\hline & 19/9/1935 & - & & & $\begin{array}{c}\text { T. Moderno, } \\
\text { Alcázar de San }\end{array}$ \\
\hline
\end{tabular}




\begin{tabular}{|c|c|c|c|c|c|}
\hline & & & & & $\begin{array}{l}\text { Juan (Ciudad } \\
\text { Real) }\end{array}$ \\
\hline & 30/10/1935 & - & & & $\begin{array}{l}\text { T. Cervantes, } \\
\text { Sevilla }\end{array}$ \\
\hline & 25/6/1935 & - & & & Ávila \\
\hline $\begin{array}{l}\text { La buena } \\
\text { guarda }\end{array}$ & & - & $\begin{array}{l}\text { de Artistas } \\
\text { Reunidos }\end{array}$ & Juan Chabás & $\begin{array}{c}\text { Valladolid, } \\
\text { Burgos, Vitoria, } \\
\text { San Sebastián, } \\
\text { Eibar, Santander, } \\
\text { Bilbao }\end{array}$ \\
\hline & $25 / 6 / 1935$ & - & & & Ávila \\
\hline $\begin{array}{l}\text { El castigo sin } \\
\text { venganza }\end{array}$ & & - & $\begin{array}{l}\text { de Artistas } \\
\text { Reunidos }\end{array}$ & Juan Chabás & $\begin{array}{c}\text { Valladolid, } \\
\text { Burgos, Vitoria, } \\
\text { San Sebastián, } \\
\text { Eibar, Santander, } \\
\text { Bilbao }\end{array}$ \\
\hline & 28/6/1935 & 1 & & & $\begin{array}{c}\text { Palacio de Carlos } \\
\text { V, Granada }\end{array}$ \\
\hline & $24 / 8 / 1935$ & 1 & & & Fuente Obejuna \\
\hline & 8/10/1935 & 10 & & & $\begin{array}{l}\text { T. Barcelona, } \\
\text { Barcelona }\end{array}$ \\
\hline Fuente Ovejuna & ¿17?/10/1935 & 1 & $\begin{array}{l}\text { Margarita } \\
\text { Xirgu }\end{array}$ & $\begin{array}{l}\text { C. de Rivas } \\
\text { Cherif }\end{array}$ & $\begin{array}{c}\text { T. Conservatorio, } \\
\text { Manresa }\end{array}$ \\
\hline & $21 / 10 / 1935$ & 1 & & & Sabadell \\
\hline & 23/10/1935 & 1 & & & $\begin{array}{c}\text { T. Olympia, } \\
\text { Barcelona }\end{array}$ \\
\hline & 16/11/1935 & 1 & & & $\begin{array}{l}\text { T. Alegria, } \\
\text { Terrassa }\end{array}$ \\
\hline & $15 / 7 / 1935$ & 1 & & & $\begin{array}{l}\text { T. Gayarre, } \\
\text { Pamplona }\end{array}$ \\
\hline & 11/9/1935 & 1 & & & $\begin{array}{l}\text { T. Victoria } \\
\text { Eugenia, San } \\
\text { Sebastián }\end{array}$ \\
\hline La Dorotea & 17/10/1935 & 1 & Carmen Díaz & $\begin{array}{l}\text { Eduardo } \\
\text { Marquina }\end{array}$ & $\begin{array}{l}\text { T. Cervantes, } \\
\text { Sevilla }\end{array}$ \\
\hline & 21/11/1935 & 2 & & & $\begin{array}{l}\text { T. Principal, } \\
\text { Valencia }\end{array}$ \\
\hline & 27/12/1935 & 7 & & & $\begin{array}{l}\text { T. Barcelona, } \\
\text { Barcelona }\end{array}$ \\
\hline $\begin{array}{l}\text { El perro del } \\
\text { hortelano }\left(^{*}\right)\end{array}$ & 28/8/1935 & 2 & \begin{tabular}{|l|} 
C. D. E. \\
Guerrero- \\
Díaz de
\end{tabular} & $\begin{array}{l}\text { Fernando Díaz } \\
\text { de Mendoza y } \\
\text { Guerrero }\end{array}$ & $\begin{array}{c}\text { Pueblo Español, } \\
\text { Montjuic, } \\
\text { Barcelona }\end{array}$ \\
\hline
\end{tabular}




\begin{tabular}{|c|c|c|c|c|c|}
\hline & & & Mendoza & & \\
\hline \multirow{2}{*}{$\begin{array}{l}\text { La Estrella de } \\
\text { Sevilla }\left(^{*}\right)\end{array}$} & 29/8/1935 & 1 & \multirow{2}{*}{$\begin{array}{l}\text { C. D. E. } \\
\text { Guerrero- } \\
\text { Díaz de } \\
\text { Mendoza }\end{array}$} & \multirow{2}{*}{$\begin{array}{l}\text { Fernando Díaz } \\
\text { de Mendoza y } \\
\text { Guerrero }\end{array}$} & $\begin{array}{c}\text { Pueblo Español, } \\
\text { Montjuic, } \\
\text { Barcelona }\end{array}$ \\
\hline & 28/9/1935 & 2 & & & $\begin{array}{c}\text { T. Poliorama, } \\
\text { Barcelona }\end{array}$ \\
\hline \multirow{8}{*}{ La dama boba } & 10/9/1935 & 18 & \multirow{8}{*}{$\begin{array}{l}\text { Margarita } \\
\text { Xirgu }\end{array}$} & \multirow{8}{*}{$\begin{array}{l}\text { C. de Rivas } \\
\text { Cherif }\end{array}$} & $\begin{array}{c}\text { T. Barcelona, } \\
\text { Barcelona }\end{array}$ \\
\hline & 18/10/1935 & - & & & $\begin{array}{c}\text { Clavé Palace, } \\
\text { Mataró }\end{array}$ \\
\hline & $20 / 10 / 1935$ & - & & & T. Fortuny, Reus \\
\hline & $22 / 10 / 1935$ & - & & & Sabadell \\
\hline & 25/10/1935 & - & & & $\begin{array}{l}\text { T. Principal, } \\
\text { Castellón }\end{array}$ \\
\hline & 13/11/1935 & - & & & $\begin{array}{c}\text { Saló Modern, } \\
\text { Tarragona }\end{array}$ \\
\hline & 19/11/1935 & - & & & T. Vigatá, Vich \\
\hline & 9/12/1935 & 4 & & & $\begin{array}{c}\text { Principal Palace, } \\
\text { Barcelona }\end{array}$ \\
\hline \multirow{5}{*}{ La siega } & 8/10/1935 & 1 & \multirow{5}{*}{$\begin{array}{l}\text { José } \\
\text { Monteagudo }\end{array}$} & \multirow{5}{*}{$\begin{array}{l}\text { José } \\
\text { Monteagudo }\end{array}$} & $\begin{array}{c}\text { Pueblo Español, } \\
\text { Montjuic, } \\
\text { Barcelona }\end{array}$ \\
\hline & 9/10/1935 & 1 & & & $\begin{array}{c}\text { Jardines de los } \\
\text { Viveros, Valencia }\end{array}$ \\
\hline & $10 / 10 / 1935$ & 1 & & & T. Circo, Albacete \\
\hline & 12/10/1935 & 1 & & & $\begin{array}{c}\text { T. San Fernando, } \\
\text { Sevilla }\end{array}$ \\
\hline & 13/10/1935 & 1 & & & $\begin{array}{c}\text { Cinema Park, } \\
\text { Huelva }\end{array}$ \\
\hline \multirow{5}{*}{ El degollado } & 8/10/1935 & 1 & \multirow{5}{*}{$\begin{array}{l}\text { José } \\
\text { Monteagudo }\end{array}$} & \multirow{5}{*}{$\begin{array}{l}\text { José } \\
\text { Monteagudo }\end{array}$} & $\begin{array}{c}\text { Pueblo Español, } \\
\text { Montjuic, } \\
\text { Barcelona }\end{array}$ \\
\hline & 9/10/1935 & 1 & & & $\begin{array}{c}\text { Jardines de los } \\
\text { Viveros, Valencia }\end{array}$ \\
\hline & $10 / 10 / 1935$ & 1 & & & T. Circo, Albacete \\
\hline & 12/10/1935 & 1 & & & $\begin{array}{c}\text { T. San Fernando, } \\
\text { Sevilla }\end{array}$ \\
\hline & 13/10/1935 & 1 & & & $\begin{array}{c}\text { Cinema Park, } \\
\text { Huelva }\end{array}$ \\
\hline $\begin{array}{l}\text { La puente del } \\
\text { mundo }\end{array}$ & 8/10/1935 & 1 & $\begin{array}{l}\text { José } \\
\text { Monteagudo }\end{array}$ & $\begin{array}{l}\text { José } \\
\text { Monteagudo }\end{array}$ & $\begin{array}{c}\text { Pueblo Español, } \\
\text { Montjuic, } \\
\text { Barcelona } \\
\end{array}$ \\
\hline \multirow{2}{*}{$\begin{array}{l}\text { La locura por la } \\
\text { honra (auto) }\end{array}$} & 9/10/1935 & 1 & \multirow[t]{2}{*}{$\begin{array}{l}\text { José } \\
\text { Monteagudo }\end{array}$} & \multirow[t]{2}{*}{$\begin{array}{l}\text { José } \\
\text { Monteagudo }\end{array}$} & $\begin{array}{c}\text { Jardines de los } \\
\text { Viveros, Valencia }\end{array}$ \\
\hline & 10/10/1935 & 1 & & & T. Circo, Albacete \\
\hline
\end{tabular}




\begin{tabular}{|c|c|c|c|c|c|}
\hline & $12 / 10 / 1935$ & 1 & & & $\begin{array}{l}\text { T. San Fernando, } \\
\text { Sevilla }\end{array}$ \\
\hline & $13 / 10 / 1935$ & 1 & & & $\begin{array}{c}\text { Cinema Park, } \\
\text { Huelva }\end{array}$ \\
\hline San Isidro, & $27 / 10 / 1935$ & 2 & Díaz de & Manuel & T. Barcelona, \\
\hline labrador & 22/11/1935 & 1 & $\begin{array}{l}\text { Artigas- } \\
\text { Collado }\end{array}$ & Collado & Barcelona \\
\hline & $11 / 1 / 1936$ & 2 & & & T. Bretón, Logroño \\
\hline La dama boba & $17 / 1 / 1936$ & - & Margarita & C. de Rivas & T. Arriaga, Bilbao ${ }^{22}$ \\
\hline & $30 / 1 / 1936$ & 1 & & & $\begin{array}{c}\text { Coliseum M. } .^{\text {a }} \\
\text { Lisarda, Santander }\end{array}$ \\
\hline La esclava de su & $21 / 5 / 1938$ & - & Carlos & Carlos & $\begin{array}{c}\text { T. Barcelona, } \\
\text { Barcelona }\end{array}$ \\
\hline galán $\left(^{*}\right)$ & $3 / 8 / 1938$ & 1 & Baena & $\begin{array}{l}\text { Miartinez } \\
\text { Baena }\end{array}$ & $\begin{array}{c}\text { T. Tívoli, } \\
\text { Barcelona }\end{array}$ \\
\hline Fuente Ovejuna & 3/7/1938 & - & $\begin{array}{l}\text { ¿Manuel } \\
\text { González? }\end{array}$ & $\begin{array}{l}\text { ¿Manuel } \\
\text { González? }\end{array}$ & $\begin{array}{l}\text { T. Español, } \\
\text { Barcelona }\end{array}$ \\
\hline $\begin{array}{l}\text { El villano en su } \\
\text { rincón }\left(^{*}\right)\end{array}$ & $\begin{array}{c}\text { ¿Noviembre } \\
1938 ?\end{array}$ & - & $\begin{array}{l}\text { Enrique } \\
\text { Borrás }\end{array}$ & - & Liceo, Barcelona \\
\hline Fuente Ovejuna & $2 / 12 / 1938$ & - & \begin{tabular}{|l|} 
Salvador \\
Soler Marí - \\
Milagros Leal
\end{tabular} & - & $\begin{array}{c}\text { T. Principal, } \\
\text { Valencia }\end{array}$ \\
\hline
\end{tabular}

22 En Lanz $(2017,15)$. 